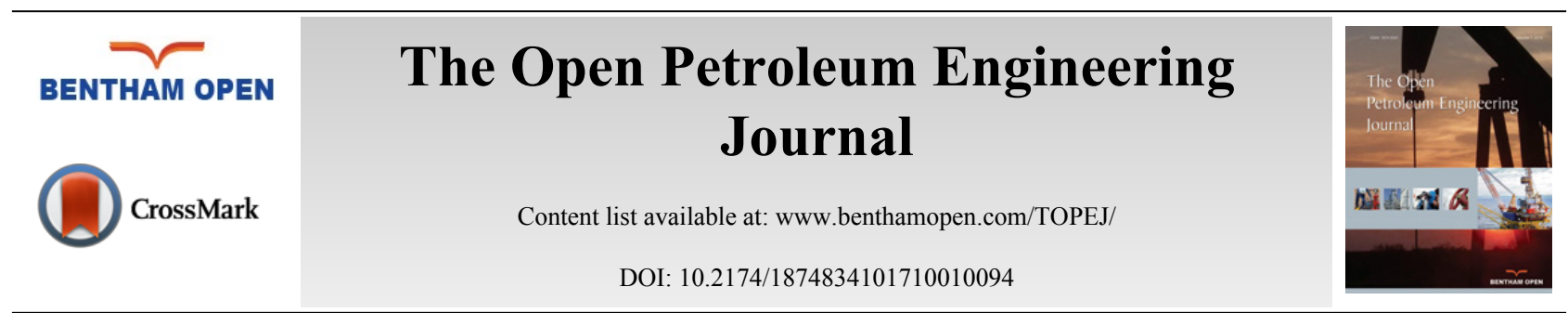

RESEARCH ARTICLE

\title{
Laboratory Study on EOR in Offshore Oilfields by Variable Concentrations Polymer Flooding
}

\author{
Kaoping Song ${ }^{*}$, Ning Sun and Yanfu Pi \\ Institute of Petroleum Engineering, Northeast Petroleum University, Daqing, Heilongjiang Province, 163318, P.R. \\ China
}

Received: December 21, 2016

Revised: February 19, 2017

Accepted: March 01, 2017

\begin{abstract}
:
Background:

Polymer flooding is the most commonly applied chemical enhanced-oil-recovery technique in offshore oilfields. However, there are challenges and risks in applying the technology of polymer flooding to offshore heavy oil development.
\end{abstract}

\section{Objective:}

This paper compared the spread law and the displacement effect of different injection modes and validated the feasibility of enhancing oil recovery by variable concentrations polymer flooding.

\section{Method:}

Two types of laboratory experiments were designed by using micro etching glass models and heterogeneous artificial cores. Furthermore, in order to determine a better polymer flooding mode, the displacement results, displacement characteristic curves and oil saturation distribution of heterogeneous artificial cores were also compared, respectively.

\section{Results:}

The experimental results showed that the recovery of variable concentrations polymer flooding was higher than that of constant concentration polymer flooding, under conditions of same total amount of polymer and similar water flooding recovery. Its sweep efficiency and displacement efficiency were also significantly higher than those of constant concentration polymer flooding. Moreover, variable concentrations polymer flooding had lower peak pressure and was at lower risk for reaching the formation fracture pressure.

\section{Conclusion:}

As a consequence, variable concentrations polymer flooding has certain feasibility for heterogeneous reservoir in offshore oilfields, and can improve interlayer heterogeneity to further tapping remaining oil in medium and low permeability layer. Conclusions of this paper can provide reference for the field application of polymer flooding in offshore oilfields.

Keywords: Offshore oilfields, Variable concentrations polymer flooding, Laboratory experiments, Micro etching glass models, Heterogeneous artificial cores.

\section{INTRODUCTION}

Polymer flooding is considered as an important technology for the strategic development of offshore oilfields in China. The implementation of polymer flooding was initiated in 2003 in Bohai oilfields, and the obvious effects on

\footnotetext{
* Address correspondence to this author at the Northeast Petroleum University, Daqing, Heilongjiang Province, 163318, P.R. China; Tel: +8618345443356; E-mails: skp2001@sina.com, 549518733@qq.com
} 
water cut reduction and oil production improvement were seen [1]. However, compared with onshore oilfields, the reservoir in offshore oilfields has characteristics of serious reservoir heterogeneity, high crude oil viscosity and high brine salinity, etc [2]. To exploit more crude oil in the limited life of the platform, there is a need for the rapid development of offshore oilfields [3 - 5]. All of these come up with higher challenges to applying the technology of polymer flooding to offshore heavy oil development [6]. Therefore, a further study of influence laws is needed, in order to maximize the recovery and minimize the economic risk of polymer flooding.

In terms of the application of polymer flooding in offshore oilfields, more and more researchers have conducted laboratory experiments, carried out numerical simulation and analyzed on-site actual data to find the displacement laws [7 - 14]. However, these studies almost focus on the effect of enhancing oil recovery (EOR) and the economic evaluation of constant concentration polymer flooding, rarely involved in variable concentrations polymer flooding [15 - 20]. For developing heterogeneous reservoirs with polymer flooding, Kaoping Song et al. proposed a method to enhance oil recovery by changing the viscosity of displacement agent continuously, which can enlarge the sweep volume in multiple-layer heterogeneous reservoir [21]. Bin Huang et al. also carried out laboratory experiments with multi-tube parallel artificial cores and heterogeneous sand-packed models to compare the effect of different schemes [22]. The above studies showed that variable viscosity polymer flooding can improve the recovery of heterogeneous reservoir more effectively. But such experiments can neither simulate the process of polymer flooding in offshore oilfields well nor can the experiments show the oil saturation distribution of each layer visually.

In this paper, based on the reservoir characteristics of Bohai SZ36-1 oilfield, we carried out laboratory experiments by using micro etching glass models and heterogeneous artificial cores, which proved that variable concentrations polymer flooding was better. We also compared the difference between remaining oil saturation of each layer and demonstrated the feasibility of variable concentrations polymer flooding in offshore oilfields.

\section{THEORETICAL SECTION}

Assume that displacement agents with different concentrations flow evenly in multiple-layer heterogeneous reservoir, as shown in Fig. (1). The differential pressure between injection well and production well in the displacement process is given as:

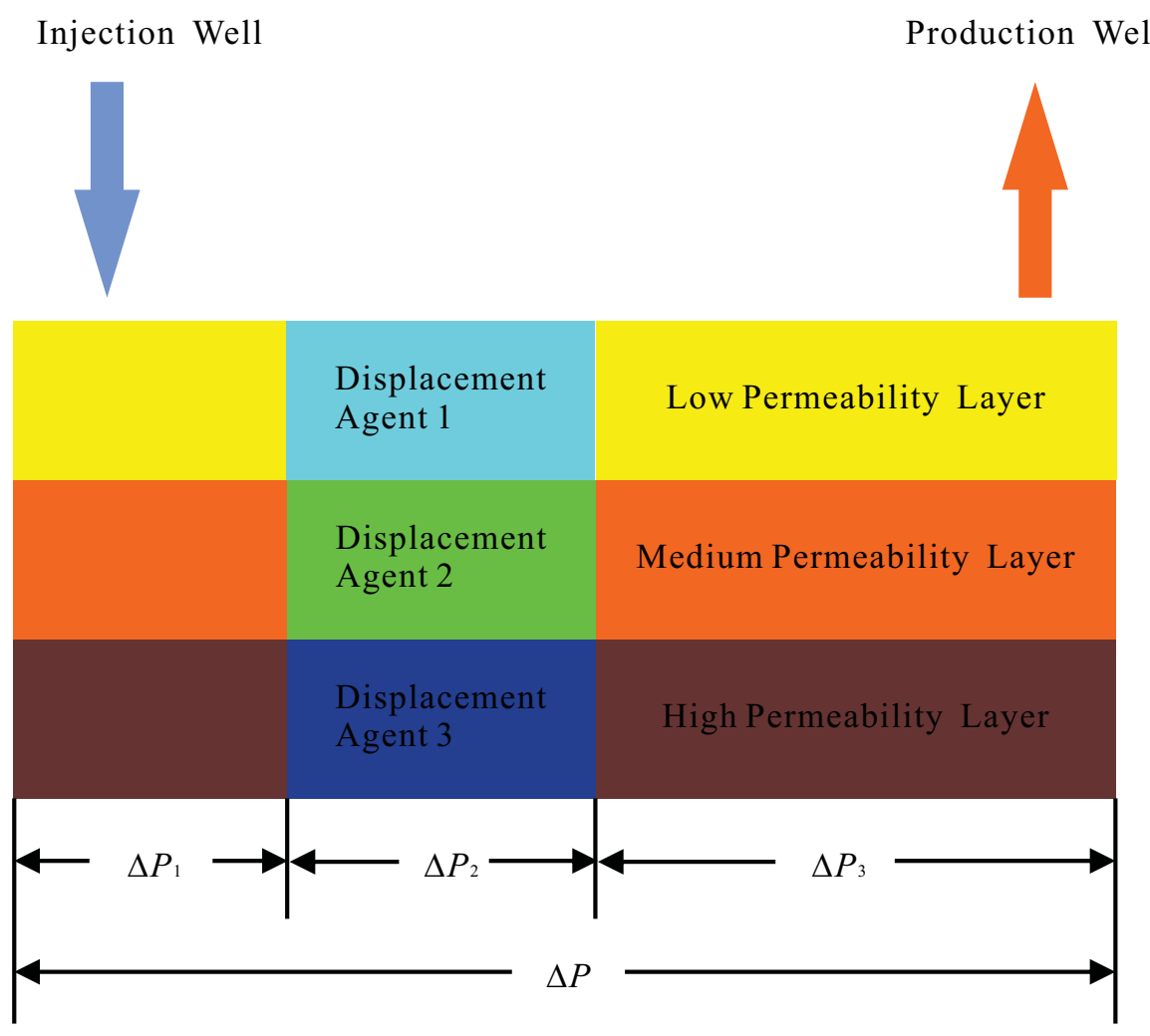

Fig. (1). Pressure distribution in multiple-layer heterogeneous reservoir. 


$$
\Delta P=\Delta P_{1}+\Delta P_{2}+\Delta P_{3}
$$

Where, $\Delta P$ is the total differential pressure between injection well and production well, $\Delta P_{1}$ is the differential pressure between injection well and displacement agent, $\Delta P_{2}$ is the effective pressure, and $\Delta P_{3}$ is the differential pressure between displacement agent and production well.

As shown in Fig. (1), the seepage resistance of each layer is different in complex reservoir because of the strong heterogeneity. If the same agent is injected into the formation, the displacement front must be uneven, thus different displacement agents with various concentrations should be injected into each layer to achieve the goal of an even front. In heterogeneous reservoir, the even front can be achieved by injecting variable concentrations agents instead of constant concentration agent. Moreover, the even front can not only enlarge sweep volume, but reduce interlayer heterogeneity in multiple-layer reservoir.

When the total differential pressure is constant, reduce $\Delta P_{1}$ and $\Delta P_{3}$, then $\Delta P_{2}$ will increase. It means that if the pressure loss of displacement agent is reduced when the agent flows in the formation, the effective pressure will increase, which can enlarge the sweep volume.

To simplify the analysis process, we assume that:

1. The formation is simplified as a one-dimensional flow channel;

2. The flow pattern of oil, water and displacement agent in the formation is linear flow;

3. The fluids are incompressible, stable and have no physical and chemical reaction with the rock surface;

4. Oil, water and displacement agent are immiscible fluids, and the flow pattern can approximately be considered as slug flow.

Based on the Darcy linear percolation law, we have

$$
\Delta P=\frac{v \mu_{\mathrm{o}} L_{\mathrm{o}} \phi}{K_{\mathrm{o}}}+\frac{v \mu_{\mathrm{w}} L_{\mathrm{w}} \phi}{K_{\mathrm{w}}}+\frac{v \mu_{\mathrm{d}} L_{\mathrm{d}} \phi}{K_{\mathrm{d}}}
$$

where, $v$ is the velocity of displacement front, $\mu_{\mathrm{o}}, \mu_{\mathrm{W}}$ and $\mu_{\mathrm{d}}$ are the viscosity of oil, water and displacement agent respectively, $L_{\mathrm{o}}, L_{\mathrm{W}}$ and $L_{\mathrm{d}}$ are the equivalent length of oil area, water area and displacement agent area respectively, $K_{\mathrm{O}}$, $K_{\mathrm{w}}$ and $K_{\mathrm{d}}$ are the equivalent permeability of oil area, water area and displacement agent area respectively, and $\phi$ is the formation porosity.

Then, Eq. $\mathbf{3}$ is obtained by changing the form of Eq. $\mathbf{2}$.

$$
v=\frac{\Delta P}{\phi\left(\frac{\mu_{\mathrm{o}} L_{\mathrm{o}}}{K_{\mathrm{o}}}+\frac{\mu_{\mathrm{w}} L_{\mathrm{w}}}{K_{\mathrm{w}}}+\frac{\mu_{\mathrm{d}} L_{\mathrm{d}}}{K_{\mathrm{d}}}\right)}
$$

Where, $\frac{\mu_{\mathrm{o}} L_{\mathrm{o}}}{K_{\mathrm{o}}}, \frac{\mu_{\mathrm{w}} L_{\mathrm{w}}}{K_{\mathrm{w}}}$ and $\frac{\mu_{\mathrm{d}} L_{\mathrm{d}}}{K_{\mathrm{d}}}$ represent the seepage resistance of oil, water and displacement agent respectively.

It can be seen from Eq. 3 that there is a certain connection between the velocity of the displacement front and the seepage resistance. For constant concentration polymer flooding, there must be differences between seepage resistance of each layer, which can lead to an uneven front.

At present, polymer flooding development in offshore oilfields mainly includes three stages: front water flooding, polymer flooding and subsequent water flooding. In contrast to the onshore fields, the offshore oilfield development requires early polymer flooding. The polymer used in most studies at present is high concentration polymer, but the seepage resistance and the injection pressure will increase greatly after the polymer being injected into the formation. If we inject the high concentration polymer continuously, the bottom hole pressure may be greater than the formation fracture pressure, which can lead to the failure of injection allocation. Therefore, constant concentration polymer flooding has certain limitations in offshore oil development. However, if we reduce the concentration of injected slugs gradually, the risk of excessive injection pressure will be lower. In addition, the seepage resistance of displacement agent will change by this means. High concentration polymer has a certain profile control effect in high permeability layer, while lower concentration polymer expand sweep volume in medium and low permeability layer. In this way, it 
effectively alleviates the interlayer contradiction caused by the difference of seepage velocity, thus greatly improves the development effects.

Two development modes are illustrated in Fig. (2).

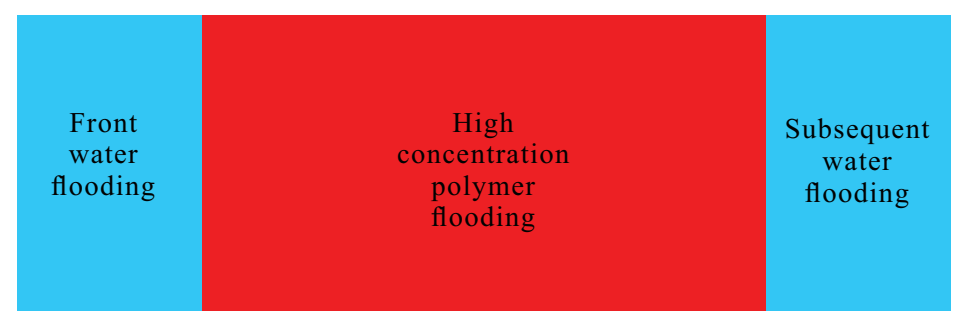

(a)

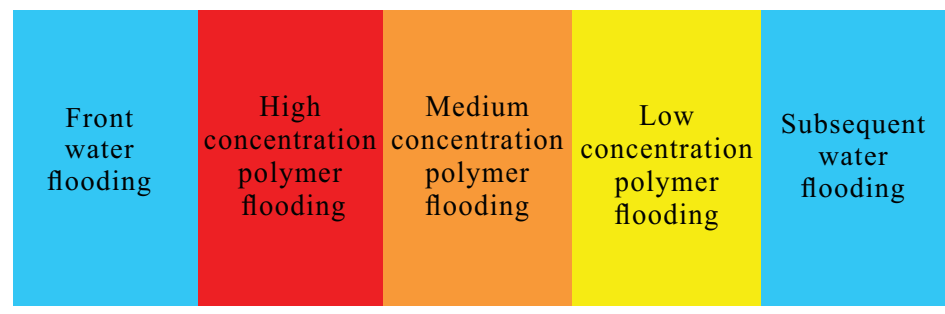

(b)

Fig. (2). Two types of polymer flooding development modes. (a) constant concentration; (b) variable concentrations.

\section{EXPERIMENTAL SECTION}

In this paper, laboratory experiments have been carried out by using micro etching glass models and heterogeneous artificial cores, and the displacement effect of two development modes was evaluated respectively.

\subsection{Experimental Materials and Equipment}

The experimental materials are as follows: Hydrophobic associating polymer HNT300 with relative molecular mass being $1600 \times 10^{4}$; Simulated formation water with salinity being $9374.13 \mathrm{mg} / \mathrm{L}$; Simulated oil, made of crude oil from offshore oilfield and kerosene in a certain proportion, with viscosity being $70 \mathrm{mPa} \cdot \mathrm{s}$ when water-bath temperature at 65 ${ }^{\circ} \mathrm{C}$; Micro etching glass models, whose dimension are $40 \mathrm{~mm} \times 40 \mathrm{~mm} \times 5 \mathrm{~mm}$ with porosity being $38.15 \%$; Heterogeneous artificial cores with average permeability being $1000 \times 10^{-3} \mu^{2}$, cemented by epoxy resin and the dimension are $300 \mathrm{~mm} \times 300 \mathrm{~mm} \times 45 \mathrm{~mm}$. The artificial cores are positive rhythm cores, and the permeability of each layer is $200 \times 10^{-3} \mu^{2}, 1000 \times 10^{-3} \mu^{2}$ and $1800 \times 10^{-3} \mu^{2}$ respectively. Several electrodes are arranged in different layers for saturation monitoring.

The experimental equipments are as follows: Constant-temperature cabinet; DV-III Brookfield viscometer; Pressure gage; LB-1 Constant flux pump; Micro pump; WCJ-801 Magnetic stirrer; Oil saturation test device; Data acquisition computer; Videocorders; Image analysis computer; Graduated cylinder.

The ion composition of simulated formation water is listed in Table $\mathbf{1 .}$

Table 1. Ion composition of simulated formation water.

\begin{tabular}{|c|c|c|c|c|c|c|c|}
\hline Ion type & $\mathbf{N a}^{+}+\mathbf{K}^{+}$ & $\mathbf{M g}^{2+}$ & $\mathbf{C a}^{2+}$ & $\mathbf{C l}$ & $\mathbf{C O}_{3}{ }^{2-}$ & $\mathbf{S O}_{4}{ }^{2-}$ & $\mathbf{H C O}_{3}{ }^{-}$ \\
\hline Ion concentration $(\mathrm{mg} / \mathrm{L})$ & 3091.96 & 158.68 & 276.17 & 5436.34 & 14.21 & 85.29 & 311.48 \\
\hline
\end{tabular}




\subsection{Experimental Method}

\subsubsection{Laboratory Study Based on Micro Etching Glass Models}

The experimental steps are as follows:

1. Place the experimental materials and the equipment into the constant-temperature cabinet, set the temperature to $65{ }^{\circ} \mathrm{C}$ and keep them heated for 4 hours;

2. Vacuum the micro etching glass models for 6 hours and saturate the models with simulated oil;

3. Set the displacement velocity to $0.03 \mathrm{~mL} / \mathrm{h}$ and inject formation water for 24 hours;

4. Inject a certain volume of polymer with constant concentration or variable concentrations, make sure the total amount of polymer used in each scheme is equal, record the experimental data and capture images during the experiments;

5. Calculate the recovery of different experimental schemes and analyze the images.

The connection mode of experimental equipment is illustrated in Fig. (3).

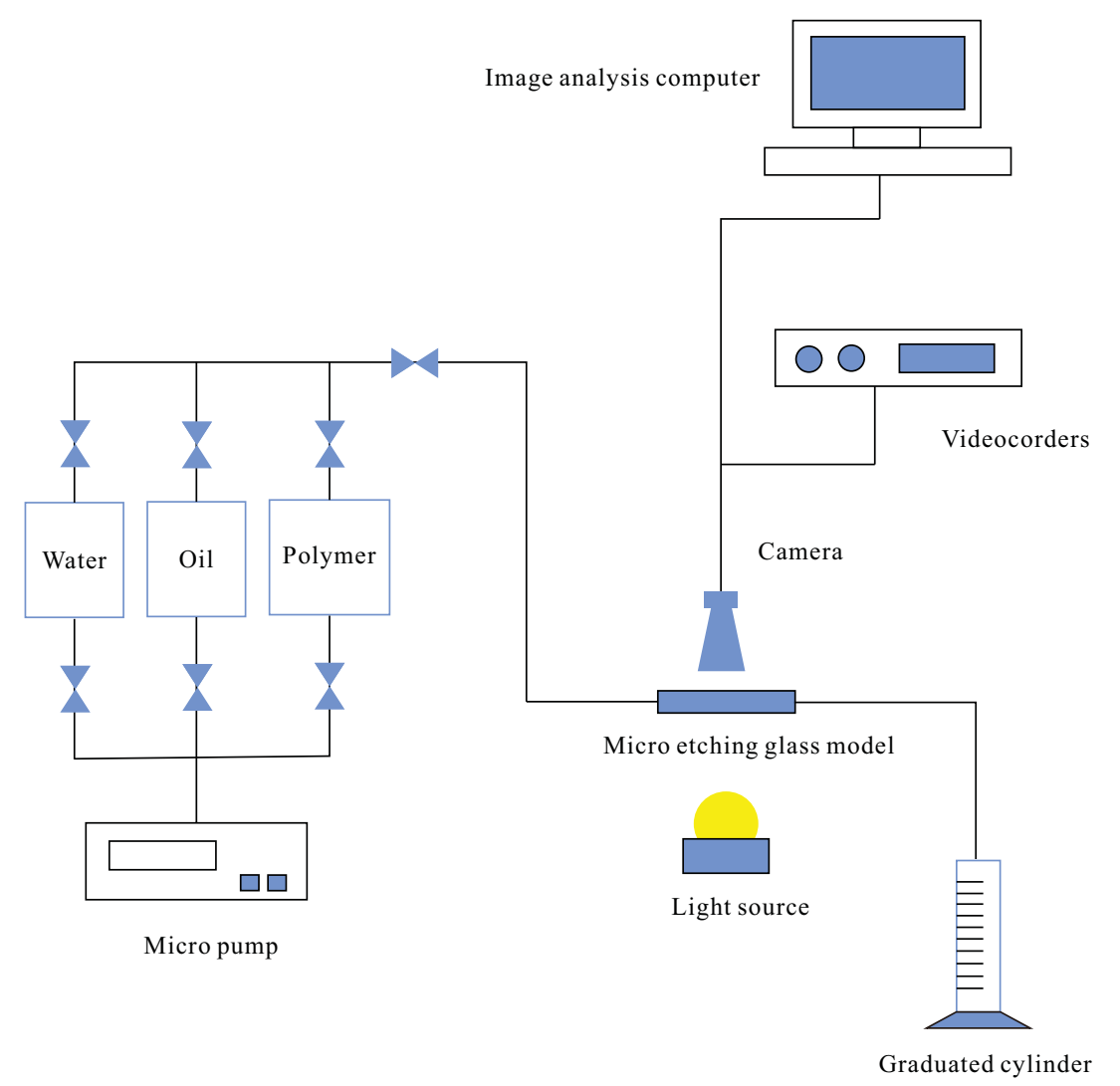

Fig. (3). Connection mode of experimental equipment (laboratory experiments based on micro etching glass models).

The experimental schemes are as follows:

1. Scheme 1-1 (constant concentration polymer flooding): set the displacement velocity to $0.03 \mathrm{~mL} / \mathrm{h}$, and inject simulated formation water for 24 hours + inject high concentration polymer solution $\left(C_{\mathrm{p}}=2000 \mathrm{mg} / \mathrm{L}\right)$ for 3 hours;

2. Scheme 1-2 (variable concentrations polymer flooding): set the displacement velocity to $0.03 \mathrm{~mL} / \mathrm{h}$, and inject simulated formation water for 24 hours + inject high concentration polymer solution $\left(C_{\mathrm{p}}=2000 \mathrm{mg} / \mathrm{L}\right)$ for 1 hour + inject medium concentration polymer solution $\left(C_{\mathrm{p}}=1600 \mathrm{mg} / \mathrm{L}\right)$ for 2 hours + inject low concentration polymer solution $\left(C_{\mathrm{p}}=800 \mathrm{mg} / \mathrm{L}\right)$ for 1 hour. 


\subsubsection{Laboratory Study Based on Heterogeneous Artificial Cores}

The experimental steps are as follows:

1. Place the experimental materials and the equipment into the constant-temperature cabinet, set the temperature to $65^{\circ} \mathrm{C}$ and keep them heated for 4 hours;

2. Vacuum the artificial cores for 4 hours, saturate the cores with simulated formation water and measure the porosity;

3. Saturate the cores with simulated oil, set the displacement velocity to $0.03 \mathrm{~mL} / \mathrm{h}$ and inject formation water until water cut reaches $50 \%$;

4. Inject a certain volume of polymer with constant concentration or variable concentrations, and make sure the total amount of polymer used in each scheme is equal;

5. Inject formation water until water cut reaches $95 \%$, record all data during the experiments, calculate the recovery of different schemes and compare the oil saturation distribution of each layer by computer.

The connection mode of experimental equipment is illustrated in Fig. (4).

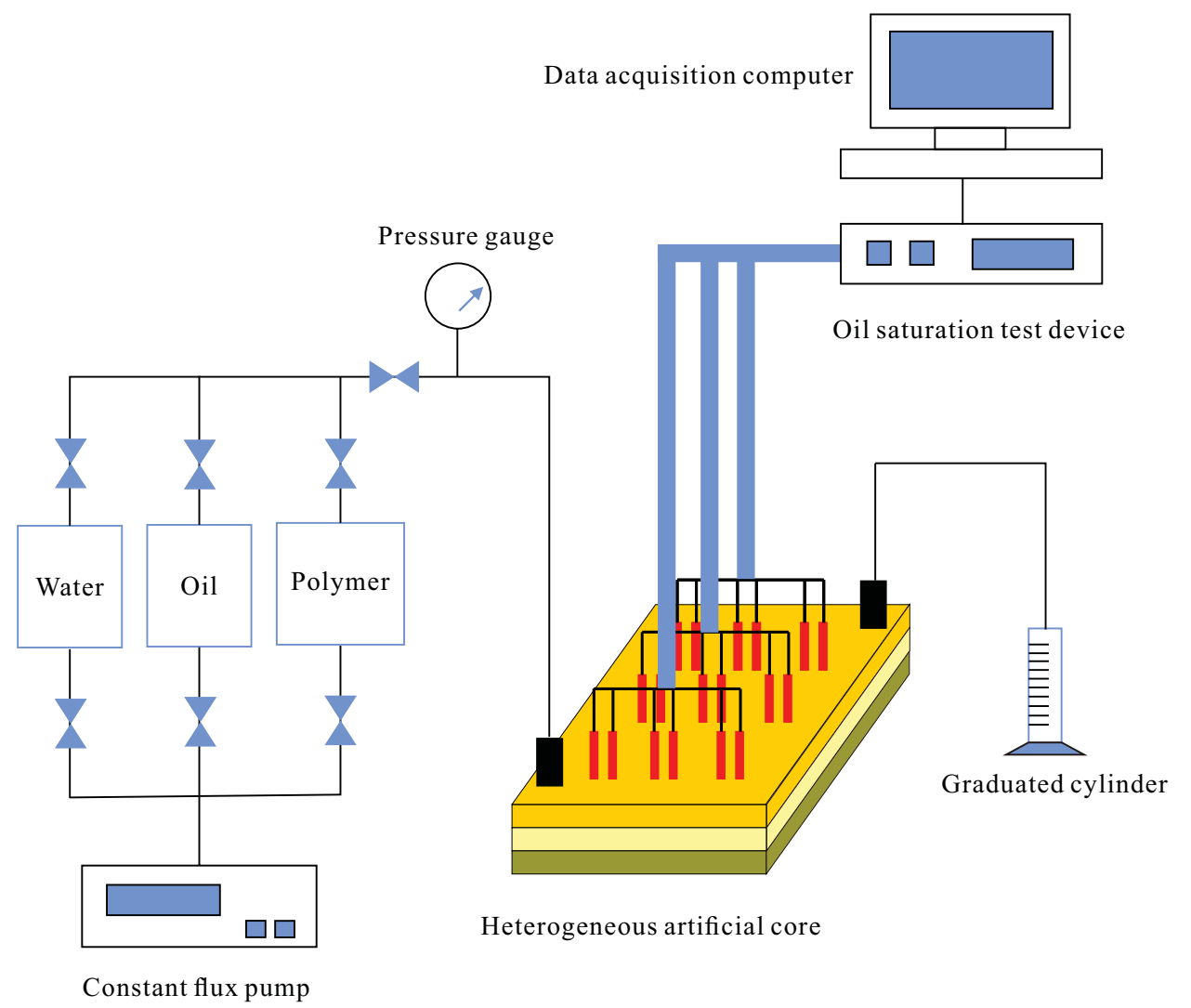

Fig. (4). Connection mode of experimental equipment (laboratory experiments based on heterogeneous artificial cores).

The experimental schemes are as follows:

1. Scheme 2-1 (constant concentration polymer flooding): set the displacement velocity to $0.3 \mathrm{~mL} / \mathrm{h}$, and inject simulated formation water until water cut reaches $50 \%+$ inject $1.2 \mathrm{PV}$ high concentration polymer solution $\left(C_{\mathrm{p}}=2000 \mathrm{mg} / \mathrm{L}\right)+$ inject simulated formation water until water cut reaches $95 \%$;

2. Scheme 2-2 (variable concentrations polymer flooding): set the displacement velocity to $0.3 \mathrm{~mL} / \mathrm{h}$, and inject simulated formation water until water cut reaches $50 \%+$ inject $0.4 \mathrm{PV}$ high concentration polymer solution $\left(C_{\mathrm{p}}=2000 \mathrm{mg} / \mathrm{L}\right)+$ inject $0.8 \mathrm{PV}$ medium concentration polymer solution $\left(C_{\mathrm{p}}=1600 \mathrm{mg} / \mathrm{L}\right)+$ inject $0.4 \mathrm{PV}$ low concentration polymer solution $\left(C_{\mathrm{p}}=800 \mathrm{mg} / \mathrm{L}\right)+$ inject simulated formation water until water cut reaches $95 \%$. 
Where, PV is referred to as the multiples of pore volume injected.

\section{RESULTS AND DISCUSSION}

\subsection{Laboratory Study Based on Micro Etching Glass Models}

We designed two schemes by using micro etching glass models, and the displacement results (shown in Fig. 5) of each scheme during different stages (shown in Table 2) were compared.

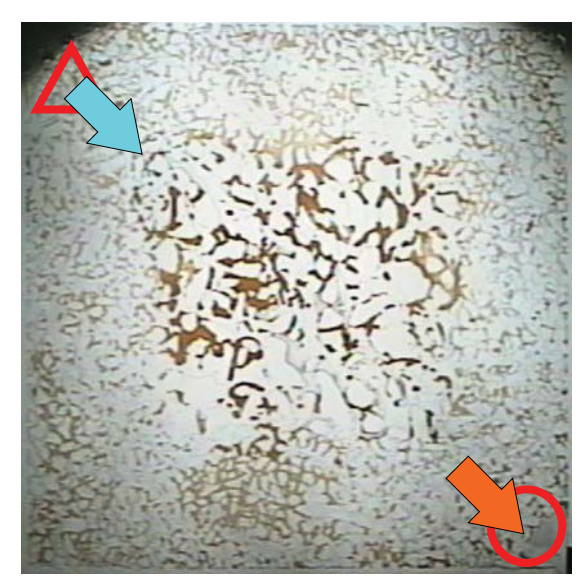

(a)

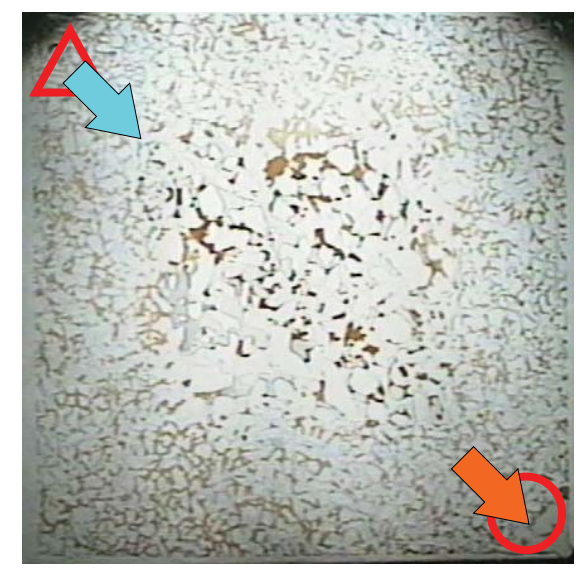

(b)

Fig. (5). Displacement results of each scheme. (a) scheme1-1; (b) scheme 1-2. Where, $\Delta$ represents injection well, and $\circ$ represents production well.

Table 2. Recovery of each scheme during different stages.

\begin{tabular}{|c|c|c|c|c|c|c|}
\hline \multirow{2}{*}{ Scheme number } & \multicolumn{2}{|c|}{ Polymer injection scheme } & \multicolumn{4}{|c|}{ Oil recovery during different stages (\%) } \\
\cline { 2 - 7 } & $\begin{array}{c}\text { Concentration } \\
\text { (mg/L) }\end{array}$ & $\begin{array}{c}\text { Injection time } \\
\text { (h) }\end{array}$ & Front water flooding & Polymer flooding & Subsequent water flooding & Total \\
\hline $1-1$ & 2000 & 3 & 51.28 & 20.15 & 2.39 & 73.82 \\
\hline \multirow{3}{*}{$1-2$} & 2000 & 1 & 50.84 & 28.36 & 2.17 & 81.37 \\
\cline { 2 - 6 } & 1600 & 2 & 1 & & & \\
\cline { 2 - 7 }
\end{tabular}

As shown in Fig. (5), we may safely draw the conclusion that there was an evident difference between the displacement effect of two schemes. The sweep efficiency of variable concentrations polymer flooding has reached 
$75.3 \%$, which was $8.9 \%$ higher than that of constant concentration polymer flooding. The displacement efficiency of variable concentrations polymer flooding was also significantly higher by comparing the remaining oil distribution nearby the mainstream line.

The results in Table 2 indicated that under conditions of same total amount of polymer and similar water flooding recovery, the recovery of variable concentrations polymer flooding was $28.36 \%$ during polymer flooding stage, which was $8.21 \%$ higher than that of constant concentration polymer flooding. This is because high concentrations polymer slug flowed into the macropores first, and subsequent lower concentration polymer slugs came into smaller pore throats gradually to displace the remaining oil, which may result in a better displacement effect.

The results confirm the findings of our earlier research. For example, Kaoping Song et. al designed a method to improve oil recovery of multiple-layer heterogeneous reservoir [21]. The results showed that variable viscosity polymer flooding was better, and the recovery was $11.18 \%$ higher than that of constant viscosity polymer flooding.

\subsection{Laboratory Study Based on Heterogeneous Artificial Cores}

\subsubsection{Comparison Between Different Displacement Characteristics}

In order to determine the seepage characteristics of heterogeneous artificial cores used in Scheme 2-1 and Scheme 2-2, the relative permeability curves under the conditions of different polymer concentrations were measured by using unstable-state method. The relative permeability curves are shown in Fig. (6).

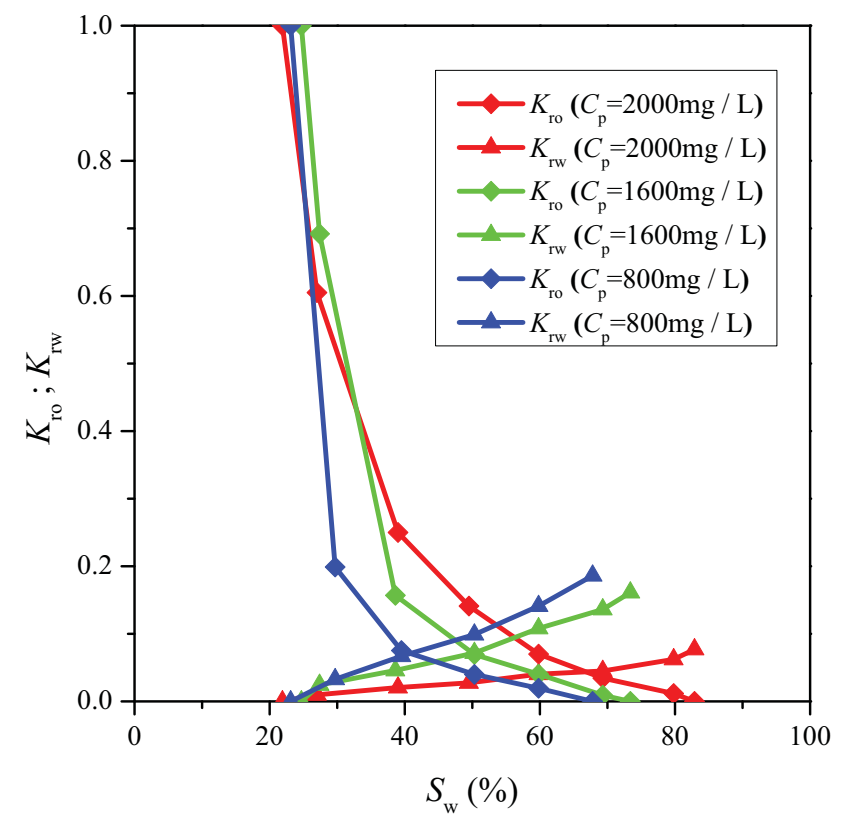

Fig. (6). Relative permeability curves under different polymer concentrations.

Fig. (6) shows the influence of polymer concentration to the relative permeability curves. Under the condition of the same water saturation, the relative permeability of water phase (polymer system) decreases and the relative permeability of oil phase increases with the increase of polymer concentration. The adsorption, mechanical capture and hydrodynamic capture of the polymer molecules exist on the wall of pore throats, and then the molecules are trapped in the cores, which narrows flow channels and reduces the flow capacity of the polymer system. In addition, there's strong hydrogen bonding between polymer molecules and water molecules, which enhances the adsorption of water molecules on the adsorption layer and reduces the relative permeability of polymer system significantly. The higher the polymer concentration, the stronger will be the effect. However, polymer molecules will not restrict the flow of oil phase significantly, and the adsorption layer formed by polymer molecules on the wall of pores can make pore throats smoother. To a certain extent, it will reduce the seepage resistance of oil phase when flowing in cores, which increases the relative permeability of oil phase.

As shown in Fig. (6), the residual oil saturation decreases with the increase of polymer concentration. On one hand, polymer molecules are crosslinking and intertwining all the time, which can effectively improve the mobility of 
polymer system and increase the microscopic sweep efficiency. On the other hand, polymer has good viscoelasticity. Its elastic deformation and tensile deformation will increase partial pressure in cores, which can result in the flow of residual oil.

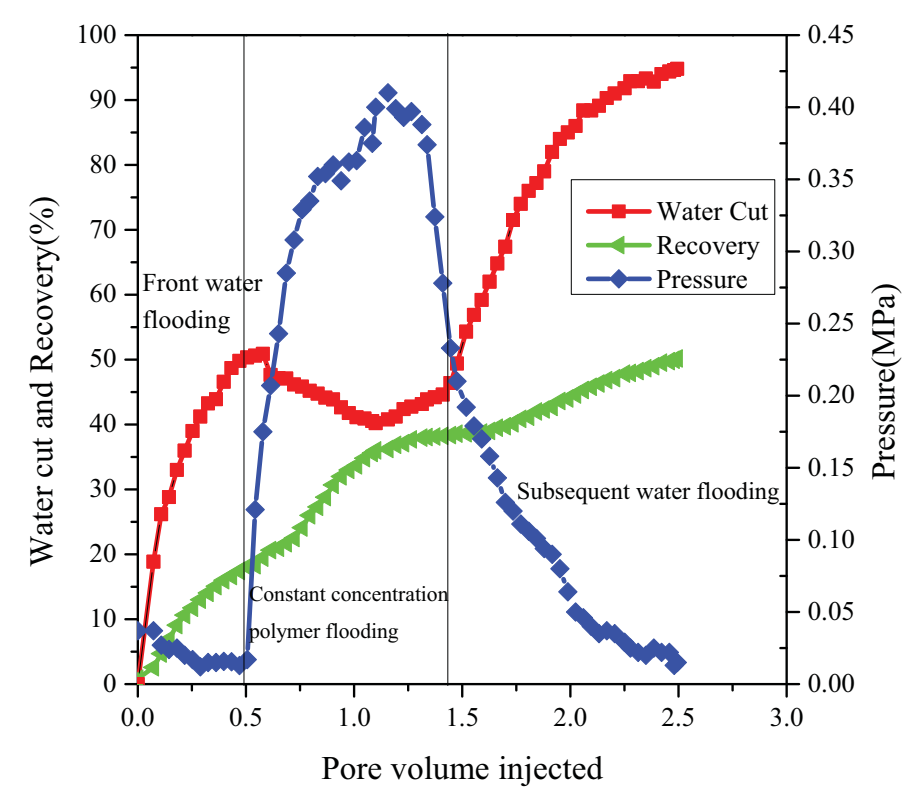

Fig. (7). Displacement characteristic curve of scheme 2-1.

We conducted two experiments by using heterogeneous artificial cores, and compared the recovery, as well as the displacement characteristic curves (shown in Figs. 7 and 8), of each scheme during different stages (shown in Table 3).

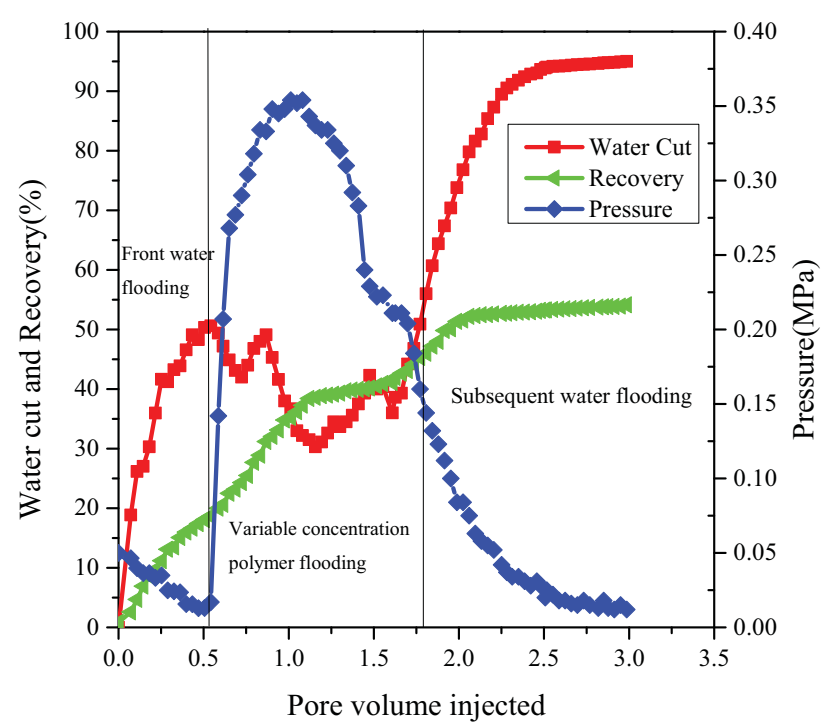

Fig. (8). Displacement characteristic curve of scheme 2-2.

As shown in Fig. (7) and Table 3, at the beginning of water flooding stage, water was injected into the pores to push the oil droplets and overcame the capillary force, which may lead to an increase of injection pressure. The crude oil was displaced by injected water once the threshold pressure was reached, and the injected water then flowed along the high permeability layer due to the existence of seepage resistance difference. With the formation of dominant channel in high permeability layer, the seepage resistance became smaller, the injection pressure reduced, the water cut rose rapidly and the increasing trend of recovery became slower.

Then 1.2 PV high concentration polymer solution $\left(C_{\mathrm{p}}=2000 \mathrm{mg} / \mathrm{L}\right)$ was injected when the water cut reached $50 \%$. The high concentration polymer played a profile control role in high permeability layer due to its high viscosity, which 
led to a sharp rise in injection pressure, and the remaining oil distributed in medium and low permeability layer began to be produced. Along with the decrease of water cut, the oil recovery rose from $18.10 \%$ to $38.24 \%$. After the pressure increased to the peak value $(0.41 \mathrm{MPa})$, the dominant channel was formed in high permeability layer. High concentration polymer solution, therefore, cannot be injected into medium and low permeability layer any more, because of the decrease of pressure and liquid absorption.

The viscosity of water was relatively low in the process of subsequent water flooding, which caused a sharp decline in pressure but a rapid rise in water cut. The ultimate recovery was $50.17 \%$ when the water cut reached $95 \%$, which indicated that there were still quantity of remaining oil exist in medium and low permeability layer.

As shown in Fig. (8) and Table 3, 0.4 PV high concentration polymer solution $\left(C_{\mathrm{p}}=2000 \mathrm{mg} / \mathrm{L}\right)$ was injected at the end of water flooding stage. High concentration polymer always flowed into the dominant channel formed in high permeability layer. It had a certain profile control effect and improved the local pressure gradient of high permeability layer, which led to a sharp rise of injection pressure. Then $0.8 \mathrm{PV}$ medium concentration polymer solution $\left(C_{\mathrm{p}}=1600\right.$ $\mathrm{mg} / \mathrm{L})+0.4 \mathrm{PV}$ low concentration polymer solution $\left(C_{\mathrm{p}}=800 \mathrm{mg} / \mathrm{L}\right)$ were injected subsequently, and the injection pressure increased slowly. As the lower concentration polymer flowed into the medium and low permeability layer, the remaining oil was produced gradually. At the same time, the water cut reduced and the recovery of polymer flooding stage was from $18.70 \%$ to $43.10 \%$.

Table 3. Recovery of each scheme during different stages.

\begin{tabular}{|c|c|c|c|c|c|c|c|c|}
\hline \multirow{2}{*}{$\begin{array}{l}\text { Scheme } \\
\text { number }\end{array}$} & \multicolumn{3}{|c|}{ Polymer injection scheme } & \multirow{2}{*}{$\begin{array}{c}\text { Core porosity } \\
(\%)\end{array}$} & \multicolumn{4}{|c|}{ Oil recovery during different stages (\%) } \\
\hline & \begin{tabular}{|c|} 
Concentration \\
$(\mathrm{mg} / \mathrm{L})$
\end{tabular} & $\begin{array}{c}\text { Injection volume } \\
\text { (PV) }\end{array}$ & \begin{tabular}{|l|} 
Viscosity \\
$(\mathrm{mPa} \cdot \mathrm{s})$
\end{tabular} & & $\begin{array}{l}\text { Front water } \\
\text { flooding }\end{array}$ & Polymer flooding & $\begin{array}{l}\text { Subsequent water } \\
\text { flooding }\end{array}$ & Total \\
\hline $2-1$ & 2000 & 0.9 & 204.5 & 25.7 & 18.10 & 20.14 & 11.93 & 50.17 \\
\hline \multirow{3}{*}{$2-2$} & 2000 & 0.3 & 204.5 & \multirow{3}{*}{26.8} & \multirow{3}{*}{18.70} & \multirow{3}{*}{24.40} & \multirow{3}{*}{11.03} & \multirow{3}{*}{54.13} \\
\hline & 1600 & 0.6 & 85.6 & & & & & \\
\hline & 800 & 0.3 & 43.2 & & & & & \\
\hline
\end{tabular}

According to the experimental results, we can easily see that the recovery of polymer flooding stage of scheme 2-2 was $24.40 \%, 4.26 \%$ higher than that of scheme 2-1. In addition, the peak value of injection pressure of scheme 2-2 was $0.35 \mathrm{MPa}$, which was 0.06 MPa lower than that of scheme 2-1. Therefore, we came to the conclusion that variable concentrations polymer flooding had advantages over constant concentration polymer flooding for tapping the remaining oil in offshore oilfields.

Early researchers have come up with very similar results. For example, Kaoping Song et. al studied the displacement effect of polymer flooding by using artificial cores, and they found that the recovery of variable viscosity polymer flooding was $4.88 \%$ higher [21]. Bin Huang et al. conducted laboratory experiments by using multi-tube parallel artificial cores [22]. The results showed that variable viscosity polymer flooding can bring better displacement effect. For variable viscosity polymer flooding, the recovery of polymer flooding stage was $4.48 \%$ higher.

\subsubsection{Comparison Between Different Distribution of Remaining Oil Saturation}

In general, the rock skeleton does not conduct electricity, and the higher the ion concentration of formation water, the smaller the resistance value. The measured resistance value of formation is mainly affected by pore shape, formation water salinity and oil-water ratio. Under the same conditions of pore shape and formation water salinity, the resistance value is only influenced by oil-water ratio. The relation curves between the oil saturation and the resistance value (shown in Fig. 9) was determined by the steady state method.

It can be seen from Fig. (9) that, the variation tendency of resistance value was approximate, suggesting that the relation curves were representative. Based on the relation curves between oil saturation and resistance value, the oil saturation distribution of each layer of heterogeneous artificial cores (at the end of polymer flooding stage) were mapped through data acquisition computer, as shown in Figs. (10) and (11).

As shown in Fig. (10), for scheme 2-1, a stable flow channel was formed in high permeability layer at the end of polymer flooding stage, and the sweep efficiency had reached $69.2 \%$. However, there was no significant formation of flow channel in medium and low permeability layer, and the oil wall had not been broken through, which indicated that constant concentration polymer flooding can not improve the interlayer heterogeneity. 


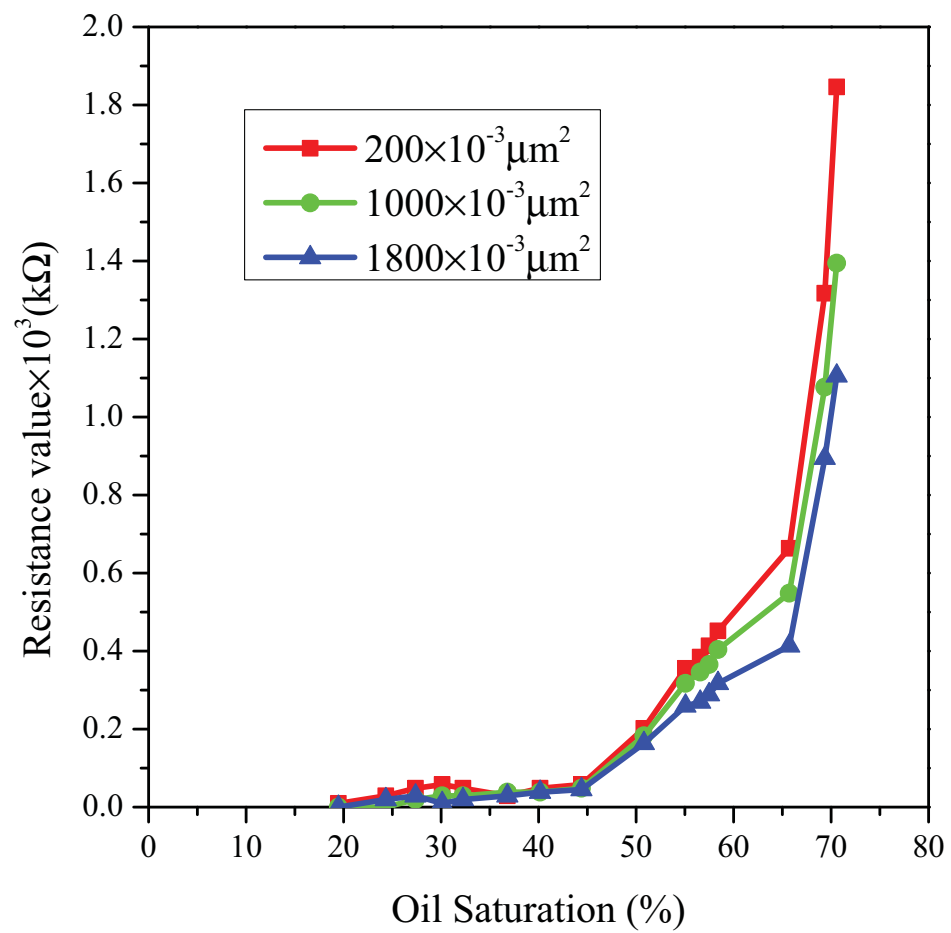

Fig. (9). Relation curves between oil saturation and resistance value.

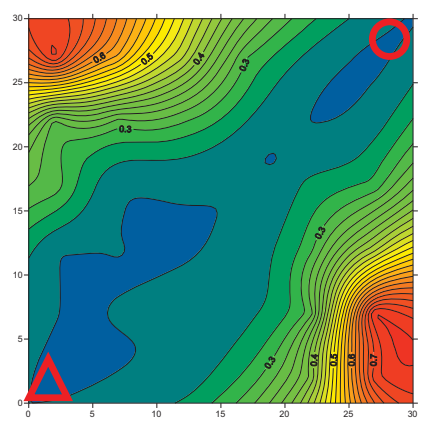

(a)

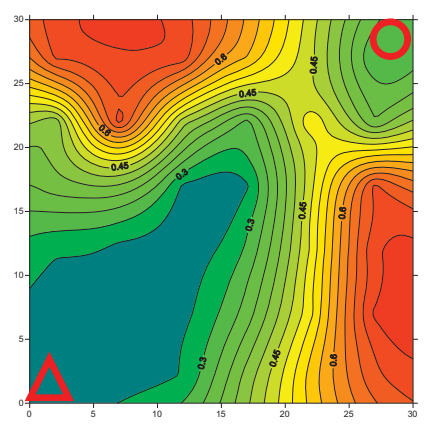

(b)

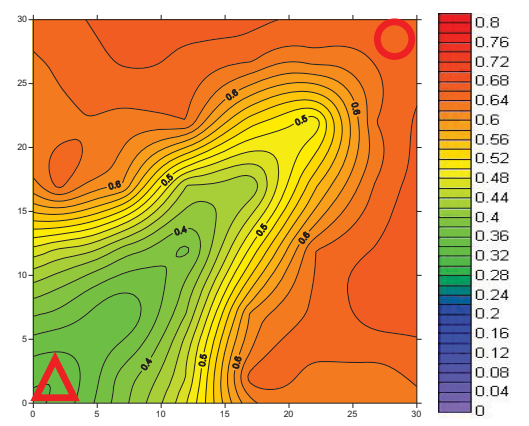

(c)

Fig. (10). Oil saturation distribution of each layer (Scheme 2-1). (a) high permeability layer; (b) medium permeability layer; (c) low permeability layer. Where, $\Delta$ represents injection well, and o represents production well.

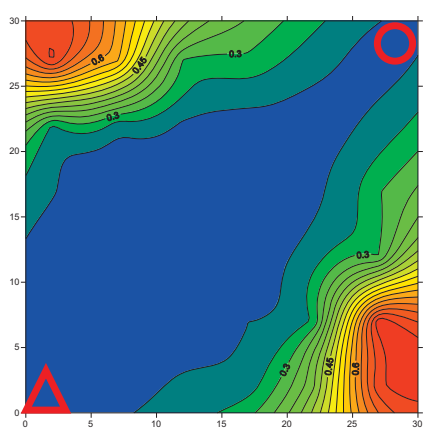

(a)

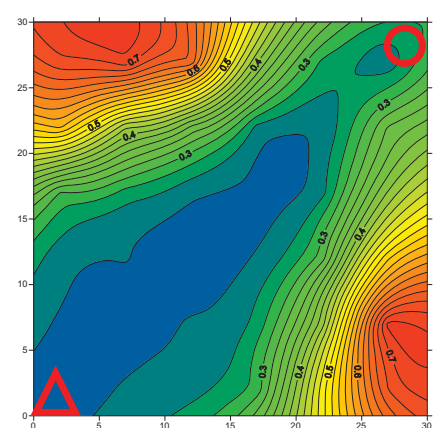

(b)

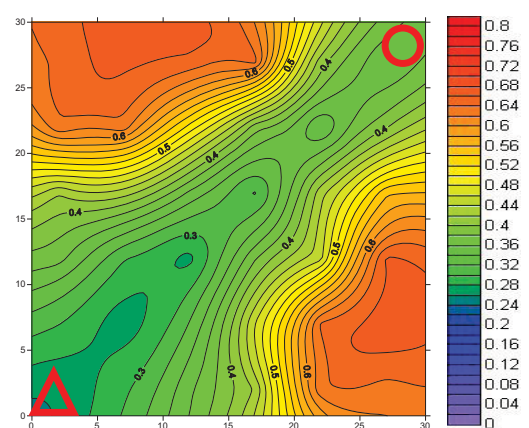

(c)

Fig. (11). Oil saturation distribution of each layer (Scheme 2-2). (a) high permeability layer; (b) medium permeability layer; (c) low permeability layer. Where, $\Delta$ represents injection well, and orepresents production well. 
As shown in Fig. (11), for scheme 2-2, a stable flow channel was formed in high and medium permeability layer at the end of polymer flooding stage, and the sweep efficiency had reached $75.7 \%$ and $61.4 \%$, respectively. The oil saturation of the area near mainstream line decreased to $22 \%$ and $24 \%$, respectively. Furthermore, the oil wall in low permeability layer would be broken through at the end of polymer flooding. The displacement efficiency and sweep efficiency of scheme 2-2 was higher, and the sweep area near the mainstream line was also larger.

Some early researchers also studied the differences between each layer. For instance, Bin Huang et al. compared the recovery of each layer by using multi-tube parallel artificial cores [22]. For variable viscosity polymer flooding, the recovery of each layer was $19.21 \%, 28.32 \%$ and $41.47 \%$, respectively. And for constant viscosity polymer flooding, the recovery of each layer was $15.78 \%, 24.66 \%$ and $35.12 \%$, respectively. Obviously, variable viscosity polymer flooding can significantly improve the displacement efficiency of each layer. But the experiments can't display the oil saturation distribution of each layer visually.

Above all, variable concentrations polymer flooding has more advantages in making further adjustment and tapping the remaining oil in offshore oilfields. It is not only because of its higher recovery and better ultimate development effect, but also it can effectively improve interlayer heterogeneity for multiple-layer heterogeneous reservoir in offshore oilfields.

\section{CONCLUSION}

In this paper, laboratory experiments were carried out with the application of micro etching glass models and heterogeneous artificial cores, and the displacement effect of different schemes were compared. The conclusions are summarized as follows.

1. The laboratory study which was based on micro etching glass models showed that the recovery of variable concentrations polymer flooding was $8.21 \%$ higher, under conditions of same total amount of polymer and similar water flooding recovery. Its sweep efficiency and displacement efficiency were also significantly higher than those of constant concentration polymer flooding.

2. The laboratory study, by using heterogeneous artificial cores, showed that the displacement effect of variable concentrations polymer flooding was better, under conditions of same total amount of polymer and similar water flooding recovery. Compared with constant concentration polymer flooding, the recovery of polymer flooding stage by variable concentrations polymer flooding was $4.26 \%$ higher, and the sweep efficiency, as well as the displacement efficiency, was significantly higher. Meanwhile, it was safer to inject variable concentrations polymer in terms of the formation fracture pressure.

3. Variable concentrations polymer flooding has a certain feasibility for heterogeneous reservoir in offshore oilfields. Front high concentration polymer always has a certain profile control effect in high permeability layer and improves the local pressure gradient, while subsequent lower concentration polymer will flow into the medium and low permeability layer to enlarge the sweep area near mainstream line. Above all, variable concentrations polymer flooding can effectively improve interlayer heterogeneity for multiple-layer heterogeneous reservoir and tap the remaining oil for further development in offshore oilfields.

\section{CONFLICT OF INTEREST}

The authors confirm that this article content has no conflict of interest.

\section{ACKNOWLEDGEMENTS}

This work is supported by National Science and Technology Major Project of China (Grant NO: 2011ZX05024). And we also would like to acknowledge the editors and the reviewers for their helpful comments and suggestions, which significantly improved the manuscript.

\section{REFERENCES}

[1] W. Zhou, J. Zhang, M. Han, W.T. Xiang, G.Z. Feng, and W. Jiang, "Application of Hydrophobically Associating Water-soluble Polymer for Polymer Flooding in China Offshore Heavy Oilfield", In: International Petroleum Technology Conference, Dubai, U.A.E, 2007. [http://dx.doi.org/10.2523/IPTC-11635-MS]

[2] Y.F. Pi, X.S. Guo, Y.M. Pi, and P. Wu, "Experimental study of chemical flooding of Suizhong 36-1 oilfield", Open Petroleum Engineering Journal, vol. 8, pp. 392-397, 2015. 
[http://dx.doi.org/10.2174/1874834101508010392]

[3] Q. Lu, Y.G. Ning, J.H. Wang, and X. Yang, "Full Field Offshore Surfactant-Polymer Flooding in Bohai Bay China", In: SPE Asia Pacific Enhanced Oil Recovery Conference, Kuala Lumpur, Malaysia, 2015. [http://dx.doi.org/10.2118/174591-MS]

[4] J.X. Gao, Y.Q. Li, J. Li, D.D. Yin, and H.F. Wang, "Experimental Study on Optimal Polymer Injection Timing in Offshore Oilfields", In: Offshore Technology Conference-Asia, Kuala Lumpur, Malaysia, 2014. [http://dx.doi.org/10.4043/24694-MS]

[5] W.T. Xiang, and W. Zhou, "Field Experience of Produced Polymer Control in Offshore Oilfield", In: SPE Enhanced Oil Recovery Conference, Kuala Lumpur, Malaysia, 2011. [http://dx.doi.org/10.2118/144277-MS]

[6] X.D. Kang, and J. Zhang, "Offshore Heavy Oil Polymer Flooding Test in JZW Area", In: SPE Heavy Oil Conference-Canada, Calgary, Alberta, Canada, 2013.

[http://dx.doi.org/10.2118/165473-MS]

[7] S.S. Yerramilli, P.L. Zitha, and R.C. Yerramilli, "Novel Insight into Polymer Injectivity for Polymer Flooding", In: SPE European Formation Damage Conference \& Exhibition, Noordwijk, The Netherlands, 2013. [http://dx.doi.org/10.2118/165195-MS]

[8] R.S. Seright, J.M. Seheult, and T. Talashek, "Injectivity characteristics of EOR polymers", SPE Reservoir Evaluation \& Engineering, vol. 12, pp. 783-792, 2009. [http://dx.doi.org/10.2118/115142-PA]

[9] R. Zhang, X. Yin, Y.S. Wu, and P.H. Winterfeld, "A Fully Coupled Model of Nonisothermal Multiphase Flow, Solute Transport and Reactive Chemistry in Porous Media", In: SPE Annual Technical Conference and Exhibition, San Antonio, Texas, USA, 2012. [http://dx.doi.org/10.2118/159380-MS]

[10] X. Zhao, Z. Rui, X. Liao, and R. Zhang, "The qualitative and quantitative fracture evaluation methodology in shale gas reservoir", Journal of Natural Gas Science and Engineering, vol. 27, pp. 486-495, 2015. [http://dx.doi.org/10.1016/j.jngse.2015.08.009]

[11] J.J. Sheng, B. Leonhardt, and N. Azri, "Status of polymer-flooding technology", Journal of Canadian Petroleum Technology, vol. 54, pp. 116-126, 2015. [http://dx.doi.org/10.2118/174541-PA]

[12] R. Zhang, P.H. Winterfeld, X. Yin, Y. Xiong, and Y.S. Wu, "Sequentially coupled THMC model for CO2 geological sequestration into a 2D heterogeneous saline aquifer", Journal of Natural Gas Science and Engineering, vol. 27, pp. 579-615, 2015. [http://dx.doi.org/10.1016/j.jngse.2015.09.013]

[13] O.C. Mogbo, "Polymer Flood Simulation in a Heavy Oil Field: Offshore Niger-Delta Experience", In: SPE Enhanced Oil Recovery Conference, Kuala Lumpur, Malaysia, 2011. [http://dx.doi.org/10.2118/145027-MS]

[14] X.D. Kang, J. Zhang, F.J. Sun, F.J. Zhang, G.Z. Feng, J.R. Yang, X.S. Zhang, and W.T. Xiang, "A Review of Polymer EOR on Offshore Heavy Oil Field in Bohai Bay, China", In: SPE Enhanced Oil Recovery Conference, Kuala Lumpur, Malaysia, 2011. [http://dx.doi.org/10.2118/144932-MS]

[15] H.Q. Jiang, F.Z. Chen, Y. Li, W. Zheng, and L. Sun, "A Novel Model to Evaluate the Effectiveness of Polymer Flooding in Offshore Oilfield", In: Offshore Technology Conference-Asia, Kuala Lumpur, Malaysia, 2014.

[http://dx.doi.org/10.4043/24777-MS]

[16] R.S. Seright, "How Much Polymer Should Be Injected During a Polymer Flood?", In: SPE Improved Oil Recovery Conference, Tulsa, Oklahoma, USA, 2016. [http://dx.doi.org/10.2118/179543-MS]

[17] P.A. Blas, and E.S. Vittoratos, "The Polymer in Polymer Flooding: Is its Value Overestimated?", In: SPE Heavy Oil Conference-Canada, Calgary, Alberta, Canada, 2014.

[http://dx.doi.org/10.2118/170104-MS]

[18] J.W. Wang, K.P. Song, and Q.R. Li, "Deep plugging experiments study in high temperature and salinity heterogeneous clastic reservoir", Open Petroleum Engineering Journal, vol. 9, pp. 216-224, 2016. [http://dx.doi.org/10.2174/1874834101609160216]

[19] W. Zhou, J. Zhang, G.Z. Feng, W. Jiang, F.J. Sun, S.W. Zhou, and Y.G. Liu, "Key Technologies of Polymer Flooding in Offshore Oilfield of Bohai Bay", In: SPE Asia Pacific Oil and Gas Conference and Exhibition, Perth, Australia, 2008. [http://dx.doi.org/10.2118/115240-MS]

[20] K. Xiao, H.Q. Jiang, Q. Wang, H. Wang, and D.F. Zhao, "Adaptability Study on Plugging Thief Zones with Asphalt Particle in Polymer Flooding Offshore Field", In: SPE Energy Resources Conference, Port of Spain, Trinidad and Tobago, 2014. [http://dx.doi.org/10.2118/169931-MS]

[21] K.P. Song, G. Ren, H.F. Xia, and Y. Zhao, "Variable viscosity enhanced oil recovery methods", Journal of Daqing Petroleum Institute, vol. 34, pp. 71-74, 2010. 
[22] B. Huang, K.P. Song, C. Fu, and Z.H. Cai, "Enhanced oil recovery by variable viscosity in polymer flooding", Sino-Global Energy, vol. 17, pp. 35-38, 2012.

\section{(C) 2017 Song et al.}

This is an open access article distributed under the terms of the Creative Commons Attribution 4.0 International Public License (CC-BY 4.0), a copy of which is available at: https://creativecommons.org/licenses/by/4.0/legalcode. This license permits unrestricted use, distribution, and reproduction in any medium, provided the original author and source are credited. 